\title{
Signaling pathways governing breast cancer stem cells behavior
}

\author{
Kai Song ${ }^{1 *}$ and Maryam Farzaneh ${ }^{2^{*}}$ (D)
}

\begin{abstract}
Breast cancer is the second common cancer and the leading cause of malignancy among females overall. Breast cancer stem cells (BCSCs) are a small population of breast cancer cells that play a critical role in the metastasis of breast cancer to other organs in the body. BCSCs have both self-renewal and differentiation capacities, which are thought to contribute to the aggressiveness of metastatic lesions. Therefore, targeting BCSCs can be a suitable approach for the treatment and metastasis of breast cancer. Growing evidence has indicated that the Wnt, NFKB, Notch, BMP2, STAT3, and hedgehog $(\mathrm{Hh})$ signaling pathways govern epithelial-to-mesenchymal transition (EMT) activation, growth, and tumorigenesis of BCSCs in the primary regions. miRNAs as the central regulatory molecules also play critical roles in BCSC self-renewal, metastasis, and drug resistance. Hence, targeting these pathways might be a novel therapeutic approach for breast cancer diagnosis and therapy. This review discusses known signaling mechanisms involved in the stimulation or prevention of BCSC self-renewal, metastasis, and tumorigenesis.
\end{abstract}

Keywords: Breast cancer, Breast cancer stem cells, Signaling pathways, miRNAs, Metastasis, Tumorigenesis

\section{Introduction}

Breast cancer (BC) is the most invasive cancer and the second common cause of malignancy among females overall [1-3]. BC involves different areas of the breast (lobules, ducts, and connective tissue) and shows various physiological properties and different clinical outcomes $[4,5]$. Based on the cancer response, BC can be divided into estrogen receptor (ER)-positive (response to estrogen signaling), progesterone receptor (PR)-positive (response to progesterone), ER/PR-positive, and human epidermal growth factor receptor-2 (HER2)-positive tumors [6-8]. Triple-negative breast cancer (TNBC) as a subtype of basal-like breast cancer (BLBC) is defined with negative expression of the ER, PR, and HER2 [9]. The main treatments for $\mathrm{BC}$ include chemotherapy [10, $11]$, radiation therapy $[12,13]$, hormone-blocking therapy [14, 15], surgery [16], and biological treatment [17].

\footnotetext{
* Correspondence: songkai2534@163.com; maryamfarzaneh2013@yahoo.com

${ }^{1}$ Xuzhou Vocational College of Bioengineering, Xuzhou 221006, Jiangsu,

China

${ }^{2}$ Fertility, Infertility and Perinatology Research Center, Ahvaz Jundishapur University of Medical Sciences, Ahvaz, Iran
}

Despite available interventions, these strategies may not always be the best treatment options for targeting $\mathrm{BC}$ metastasis [18]. Therefore, a better understanding of the molecular mechanisms involved in tumorigenesis of BC is required to develop more effective therapeutic strategies $[19,20]$. Breast cancer stem cells (BCSCs) are a small population of $\mathrm{BC}$ cells that play a critical role in the metastasis of $\mathrm{BC}$ to other organs in the body [21]. BCSCs have the ability to self-renew and to differentiate into specialized cells that are found in malignancy [22, 23]. Accumulating evidence shows that BCSCs are the leading cause of tumor progression and resistance against conventional therapy [24-26]. Therefore, targeting BCSCs may be an appropriate approach for the treatment of $\mathrm{BC}$ [27-30]. This review discusses known signaling mechanisms involved in the stimulation or prevention of $\mathrm{BCSC}$ self-renewal, metastasis, and tumorigenesis.

(c) The Author(s). 2021 Open Access This article is licensed under a Creative Commons Attribution 4.0 International License, which permits use, sharing, adaptation, distribution and reproduction in any medium or format, as long as you give appropriate credit to the original author(s) and the source, provide a link to the Creative Commons licence, and indicate if changes were made. The images or other third party material in this article are included in the article's Creative Commons licence, unless indicated otherwise in a credit line to the material. If material is not included in the article's Creative Commons licence and your intended use is not permitted by statutory regulation or exceeds the permitted use, you will need to obtain permission directly from the copyright holder. To view a copy of this licence, visit http://creativecommons.org/licenses/by/4.0/. The Creative Commons Public Domain Dedication waiver (http://creativecommons.org/publicdomain/zero/1.0/) applies to the data made available in this article, unless otherwise stated in a credit line to the data. 


\section{Cellular and molecular characteristics of BCSCs}

In recent years, the existence of BCSCs or breast cancerinitiating cells (BCICs) in BC has been confirmed [31-33]. BCSCs as a subset of cancer cells exhibit similar properties with normal stem cells [34]. These cells have a slow cell cycle and the potential to divide asymmetrically and to seed tumors when transplanted into a host $[35,36]$. BCSCs have antioxidative, tumorsphere formation, tumorigenicity, and chemoresistance properties [37]. Based on cell surface marker expression (by fluorescence-activated cell sorting (FACS)), BCSCs are CD44(+)/CD24(-/low) tumorigenic cells that initiate tumors in xenografts $[34,38]$. CD44 is a cell surface glycoprotein and stemness marker in BCSCs [39]. CD44 binds to hyaluronic acid (HA) and mediates the interactions between cell/cell and cell/matrix proteins such as matrix metalloprotease (MMP) and osteopontin (OPN) $[37,40]$. Therefore, the HA hydrogel might be an efficient strategy that targets BCSCs [37]. CD24 is a glycosylated cell surface protein that negatively controls the function of CXCR4 (chemokine receptor) and regulates BCSC metastasis and proliferation $[18,41]$. Gene expression of embryonic stem cell factors, including Oct4, Nanog, SOX2, and DNA (cytosine-5)-methyltransferase 1 (DNMT1), is observed in BCSCs [36]. It was validated that BCSCs express CD326 (EpCAM), aldehyde dehydrogenase (ALDH), epithelialspecific antigen (ESA), and E-cadherin [42, 43]. The ALDH1 enzyme is a useful therapeutic target that regulates BCSC functions and malignancies [44, 45]. EpCAM by Wnt signaling can stimulate cell adhesion, proliferation, and invasion of BCSCs [46]. CD36 through uptaking fatty acids and induction of STAT3 and nuclear factor kappa B
(NFkB) can promote expression of the stem cell marker OCT4, metastasis, and migration of BCSCs [47, 48]. Histone deacetylases (HDACs) such as HDAC1 and HDAC7 play essential roles in BCSC maintenance [49]. CD47, CD133, CD166, CD61, ABCG2, and Lgr5 are the other markers used for the isolation of BCSCs [50] (Fig. 1).

There is a high degree of intertumor and intratumor heterogeneity in breast cancer [51, 52]. Thus, a single tumor may contain BCSCs with distinct molecular profiles $[53,54]$. Based on immunohistochemical analyses, cells with the CD44+CD24-/low phenotype are not enough to characterize BCSC. Several candidate markers such as the ESA antigen, ALDH1 expression, Prominin1 (CD133), and CD131 and the capacity to form spheroid can be independent factors for the characterization of BCSCs $[49,55,56]$.

\section{Critical signaling pathways involved in the stimulation or prevention of BCSC propagation and metastasis}

Tumor microenvironment and signaling pathways have critical roles in the propagation and differentiation of BCSCs [57, 58] (Fig. 2). Growing evidences have indicated that the Wnt/ $\beta$-catenin, NFкB, BMP2, Notch, STAT3, and hedgehog (Hh) signaling pathways govern epithelial-to-mesenchymal transition (EMT) activation, growth, and tumorigenesis of BCSCs in the primary regions [38, 59-62]. However, many of these crucial signaling pathways play important functional roles in normal stem cells $[63,64]$. Several specific molecules, including NFkB, BCL6, SOX2, FOXC2, and hypoxia-

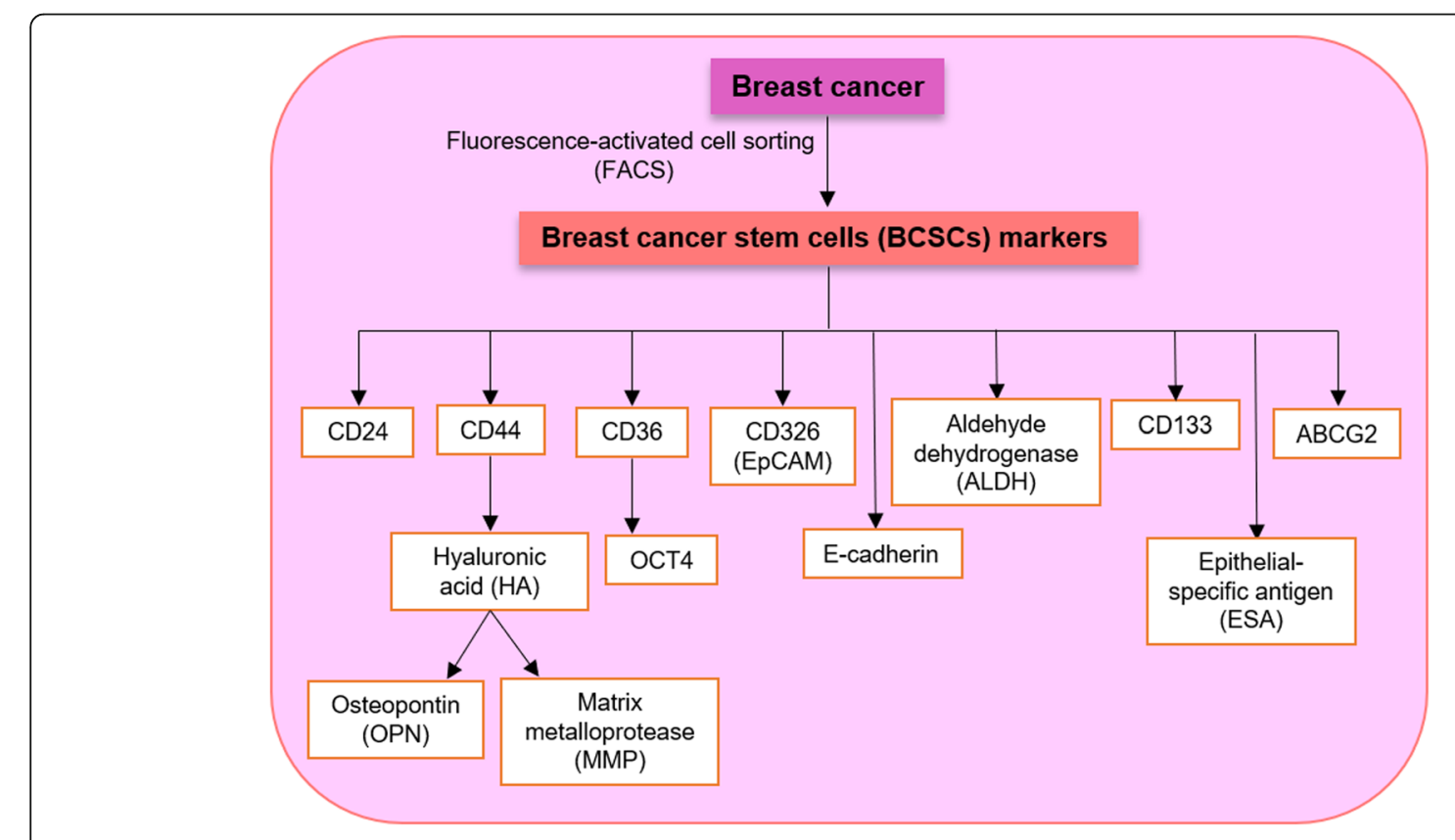

Fig. 1 Cellular and molecular characteristics of breast cancer stem cells (BCSCs) 


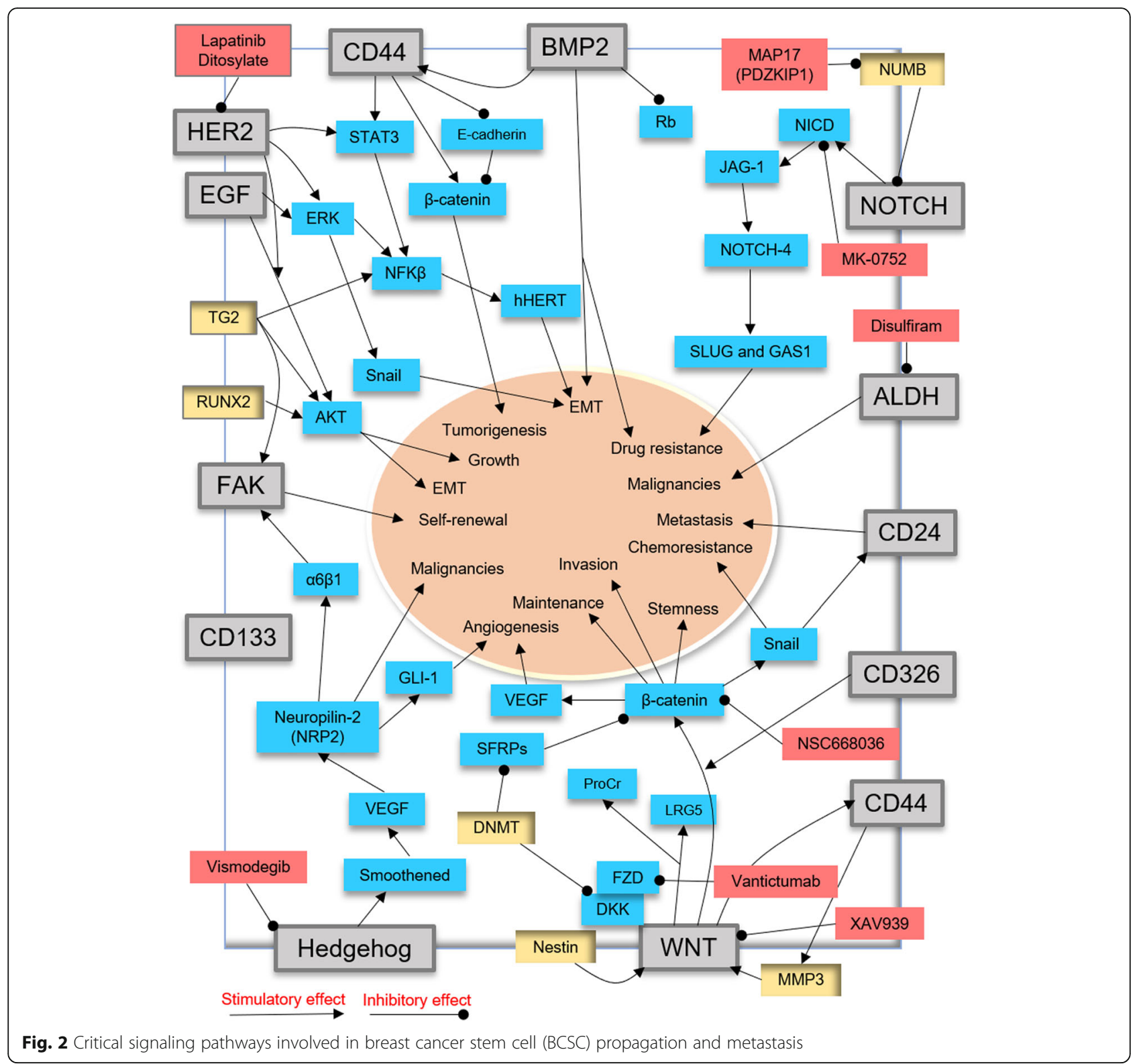

inducible factor-1 (HIF1), have been contributed to BCSC EMT and malignancies [39]. Recent studies showed that the Wnt-, STAT3-, HDAC-, and estrogen receptor alpha (ESR1)-related pathways can cause TNBC-associated BCSCs (TNBCSC) to undergo unexpected differentiation, EMT, and metastasis $[49,65]$.

\section{Signaling pathways induced by CD44 in BCSCs}

$\mathrm{CD} 44$ is known to cooperate with the receptor tyrosine kinase (RTK) and regulate BCSC proliferation and migration [39]. Blockade of CD44 impairs the properties of BCSCs, including cell adhesion, malignancy, progression, metastasis, EMT, and therapy resistance [39, 66]. Several signaling pathways such as Wnt/ $\beta$-catenin, PI3K/Akt, RasMAPK, and Rho GTPases are stimulated by CD44 [67,
68]. Thus, CD44 may be a predictor biomarker for BCSC isolation and therapy resistance [69]. However, CD44 is not a suitable marker for the detection of luminal BCSCs (CD44-/CD24+ or CD44-/CD24-) [39, 70]. CD44 can suppress the formation of the E-cadherin/ $\beta$-catenin complex and enhance nuclear $\beta$-catenin and genes related to cell invasion and tumorigenesis in BCSCs [71]. CD44 also interacts with STAT3 and NF-kB to activate the catalytic subunit of telomerase (hTERT), enhance metastasis, and trigger the EMT process in BCSCs $[69,72,73]$.

\section{WNT signaling}

The Wnt pathway plays a pivotal role in BCSC phenotype shaping, proliferation, migration, chemoresistance, and radioresistance $[62,74]$. Canonical and noncanonical 
Wnt signaling by targeting CD44 promotes the "stemness" of BCSCs $[75,76]$. The Wnt/ $\beta$-catenin/TCF4 axis through the Snail protein promotes the expression of miR-125b and chemoresistance in BCSCs [77]. Snail enhances the expression of CD44 marker and ALDH activity in BCSCs [78]. Protein C receptor (ProCr) and LRG5 are novel Wnt targets and potent biomarkers of BCSCs $[79,80]$. MMP3 has been proven that targets Wnt signaling and contributes to the maintenance of BCSCs [81]. Nestin is a type VI intermediate filament protein that positively targets the $\mathrm{Wnt} / \beta$-catenin pathway and enhances the metastatic ability of BCSCs [82]. DNMT has been proposed to inactivate the cytoplasmic $\beta$ catenin antagonists such as secreted frizzled-related proteins (SFRPs) and DICKKOPF protein (DKK) and to promote the expression of $\mathrm{Wnt} / \beta$-catenin signaling in BCSCs $[83,84]$. Therefore, targeting $\mathrm{Wnt} / \beta$-catenin signaling may be a potent marker for removing BCSCs [18, 71]. Recent studies showed that NSC668036 targeted the PDZ domain and suppressed Disheveled (Dvl) and FZD interactions in Wnt/ $\beta$-catenin signaling (pre-clinical trial) [85]. OMP-18R5 (Vantictumab) is a monoclonal antibody against FZD receptors that targets FZDs and blocks BCSC growth (phase I) [86]. XAV939 has been demonstrated that interacts with the type 1 and 2 tankyrase-binding domain (TBD) of the Axin molecule and blocks $\mathrm{Wnt} / \beta$-catenin signaling in BCSCs (phase I) [85]. PKF118-310 (PKF) is a small molecule inhibitor of Wnt $/ \beta$-catenin signaling that targets BCSCs in a HER2overexpressing mouse model [87]. Pyrvinium pamoate (PP) is an anti-helminthic drug and a WNT pathway suppressor that inhibits the expression of the NANOG, SOX2, and OCT4 genes, and the growth of BCSCs [88].

\section{BMP2 signaling}

In breast cancer xenograft models, BMP-2 can promote EMT transition and bone metastasis [89]. BMP2 via targeting $\mathrm{CD} 44$ expression and suppressing the $\mathrm{Rb}$ signaling pathway induces EMT, stemness, and chemoresistance in BCSCs [89]. Activation of the PI3K/ Akt pathway as well as $\mathrm{Rb}$ interaction with $\mathrm{CD} 44$ has been shown to play essential roles in BMP-2-dependent EMT in BCSCs [89]. However, BMPs are able to cause G1 arrest, increase apoptosis, and suppress BCSC proliferation [90]. Therefore, the BMP family may have dual behaviors in stimulation or suppression of BCSCs [91]. Thus, employing BMP family inhibitors may be useful for targeting BCSCs $[49,92,93]$.

\section{Hedgehog signaling}

Hedgehog signaling by interaction with the Smoothened (SMO) protein can influence BCSC stemness and malignancies $[49,94]$. Neuropilin-2 (NRP2) is a VEGF receptor that stimulates the expression of glioma-associated oncogene-1 (GLI-1) and $\alpha 6 \beta 1$ integrins and contributes to BCSC initiation [95]. GLI-1 by promoting angiogenesis accelerates BCSC progression [96]. Studies suggest that $\alpha 6 \beta 1$ integrins can trigger focal adhesion kinase (FAK) signaling and mediate BCSC self-renewal ability [97]. Therefore, targeting the VEGF/NRP2, $\alpha 6 \beta 1$, GLI1, and FAK signaling pathways can provide an attractive strategy for BC treatment [98]. Genistein is an isoflavone component present in soy products that has been shown to suppress hedgehog downstream signaling and block BCSC growth and survival [99]. Besides, aqueous extract of Trametes robiniophila Murr (Huaier) by blocking hedgehog downstream signaling can decrease BCSC growth, self-renewal, and proliferation $[100,101]$.

\section{Notch signaling}

The Notch pathway through JAG-1 and NOTCH-4 can stimulate and maintain the invasion, mesenchymal-like properties, and drug resistance of BCSCs [102, 103]. NOTCH4 by targeting SLUG and GAS1 is involved in BC development [104]. In normal cells, the NUMB protein blocks the Notch intracellular domain (NICD) in the cytoplasm and inhibits the Notch pathway. miR146a has been reported to suppress the function of NUMB, activate the Notch pathway, and trigger the formation of BCSCs [105]. Thus, downregulation of miR146a and miR-146b expression may weaken the capacity for self-renewal in BCSCs [106]. MAP 17 (PDZKIP1) is a small cargo protein that negatively regulates the NUMB activity, activates the Notch pathway, and promotes the maintenance of BCSCs [107]. 6-Shogaol as a gingerderived compound by targeting the expression of the Notch-Hes1-Cyclin D1 (CYLD) axis can suppress autophagy and apoptosis and then blocks the growth of BCSCs [108]. MK-0752 is a gamma-secretase inhibitor that inhibits the NICD domain and targets the BCSC population (phases I and II) [109]. Vismodegib (GDC0449) is a Notch/hedgehog inhibitor drug that inhibits BCSC growth in tamoxifen-resistant breast cancer (phase I) [110] (http://clinicaltrials.gov).

\section{PI3K-AKT signaling}

Epidermal growth factor receptor (EGFR/HER)-related signaling have been implicated in the pathogenesis of BCSCs and resistance to chemotherapeutic drugs [111, 112]. This signaling activates molecules such as STAT3, protein kinase $\mathrm{B}$ (PKB or $\mathrm{AKT})$, and tyrosine kinase Src and stimulates the MAPK (Ras/Raf/Mek/Ek), PI3K/Akt, and STATs pathways [35]. PI3K-AKT signaling is required for BCSC phenotype, EMT, and drug resistance [113]. The role of PI3K/Akt in BCSCs may be mediated by HER2 [114]. HER1- and HER2-positive BCSCs are able to self-renew $[115,116]$. HER2 dysregulation leads to a rise in the phosphorylation of Akt in the ALDH+ 
population of BCSCs [35]. Therefore, the effects of HER2 signaling in BCSCs can be increased through the PI3K/Akt pathway [35]. Transglutaminase (TG2) has been shown that stimulates NFk $\beta$, Akt, and FAK signaling and initiates BCSC growth and survival [117]. Tbox transcription factor 3 (Tbx3) through FGF signaling is associated with BCSC phenotypes and oncogenesis [118, 119]. In addition, the ZFHX3 transcription factor by enhancing TBX3 transcription increases the proliferation and tumor growth of BCSCs [120]. A recent study indicated that Runt-related transcription factor 2 (RUNX2) by activating the PI3K/AKT pathway contributes to tumorigenicity, metastasis, and EMT in BCSCs [121]. It has been reported that Disulfiram (DS) as an antialcoholism drug can inhibit NFKB activation, inhibit ALDH enzymatic activity, and reduce BCSC stemness and chemoresistance [122]. Everolimus (RAD001) is a PI3K/Akt/mTOR pathway inhibitor that blocks BCSC growth [123, 124]. Lapatinib ditosylate (NCT01868503) by targeting EGFR/HER2 impacts on the subpopulation of BCSCs (phase II) [125] (http://clinicaltrials.gov/).

\section{Signaling pathways induced by miRNAs in BCSCs}

Recently, studies have been suggested that epigenetic changes such as DNA methylation and histone modifications enhance the events of BCSC metastasis [126-128]. miRNAs are epigenetic modulators that target mRNAs without modifying the gene sequences $[129,130]$. In human cancer, miRNA expression can be controlled by epigenetic modifications [131]. miRNAs also play an important role in the proliferation, migration, and invasion of BCSCs [132-135]. The expression of microRNAs can be deregulated in BCSCs [130]. Several miRNAs including mir-21, mir-22, mir-29a, and mir-221/222 increase tumorigenesis, and miR-34a, miR-628, miRNA-140-5p, and miRNA-4319 decrease metastasis in BCSCs [39, 136, 137].

\section{Stimulation of tumorigenesis}

miRNAs as the central regulatory molecules serve critical roles in BCSC self-renewal, metastasis, and drug resistance [138-140] (Fig. 3). miR-21 by targeting the phosphatase and tensin homolog (PTEN) protein stimulates AKT/ERK1/2 signaling and contributes to the BCSC progression, EMT, and metastasis [113]. LY294002 and U0126 as the inhibitors of the PI3K-AKT and ERK1/2 pathways suppress EMT and BCSC phenotype [113]. miR-22 has been shown to target the TET (ten eleven translocation) family of methylcytosine dioxygenases and inhibit demethylation of the miR-200 promoter, promote EMT, BCSC stemness, and metastasis [141]. miR-31 targets Wnt/ $\beta$-catenin signaling and increases BCSC stemness and tumorigenesis [142]. It has been evident that miR-29a represses SUV420H2 (a histone methyltransferase) and promotes EMT progress, migration, and metastasis in BCSCs [143]. miR-124 through targeting STAT3 regulates the HIF-1 pathway and enhances doxorubicin (DOX) resistance of BCSCs [144]. miR-125b has been suggested that targets the Snail protein and increases the CD44+ and chemoresistance BCSCs [77]. miR-1287-5p through PI3K/AKT signaling plays critical roles in the prognosis and survival of BCSCs [145]. PIK3CB is a PI3Kinase pathway chemical inhibitor that interacts with miR-1287-5p and suppresses breast carcinogenesis [145]. It has been validated that miR-137 via targeting BCL11A (a zinc-finger transcription factor) and Wnt signaling enhances FSTL1 levels and chemoresistance in BCSCs [146]. The hypoxic microenvironment around BCSCs can induce the expression of miR-210. Hypoxia-mediated miR-210 by targeting E-cadherin improves BCSC invasion and proliferation [147]. miR-155 enhances BCSC stemness markers, including CD44, CD90, and ABCG2. Thus, downregulation of miR-155 promotes DOX sensitivity in BCSC [148]. It has been shown that miR-9 and miR-221 via targeting multiple genes involved with carcinogenesis are able to promote BCSC stemness and the capacity for tumor cell renewal [149]. miR-9 by targeting forkhead box O1 (FOXO1), E-cadherin, and leukemia inhibitory factor receptor (LIFR) promotes the BCSC recurrence and invasiveness [150]. miR-221/222 has been reported to regulate the expression of PTEN and enhance the growth and maintenance of BCSC [151]. Some findings suggest that miR-146a and miR-146b by targeting the Notch pathway are involved in the development of BCSCs [105].

\section{Suppression of tumorigenesis}

Some miRNAs may act as tumor suppressors and overcome tumorigenesis and drug resistance in BSCS [138, 152]. miR-34a is an important miRNA that targets the insulin-like growth factor II (IGFII), mRNA-binding protein (IMP3)-induced stemness, and $\mathrm{Wnt} / \beta$-catenin signaling and decreases BCSC self-renewal [153]. miR-628 by targeting SOS Ras/Rac guanine nucleotide exchange factor 1 (SOS1) inhibits BCSC migration and invasion [154]. miR-140-5p as a critical tumor suppressor blocks the Wnt/B-catenin, SOX2, and SOX9 pathways and inhibits the growth, tumorsphere formation, and progression of BCSCs $[155,156]$. This miRNA through the Wnt1/ABCB1 pathway promotes the sensitivity of BCSCs to Dox [156]. miR-142-3p by targeting $\beta$-catenin pathway can reduce CD44, CD133, ALDH1, and radioresistance in BCSCs [157]. miR-4319 can suppress the expression of the E2F2 transcription factor and decrease the tumorigenicity of TNBCSC [158]. Another investigation shows that miR-130a-3p by targeting the expression of RAB5B (member of RAS oncogene family) inhibits 


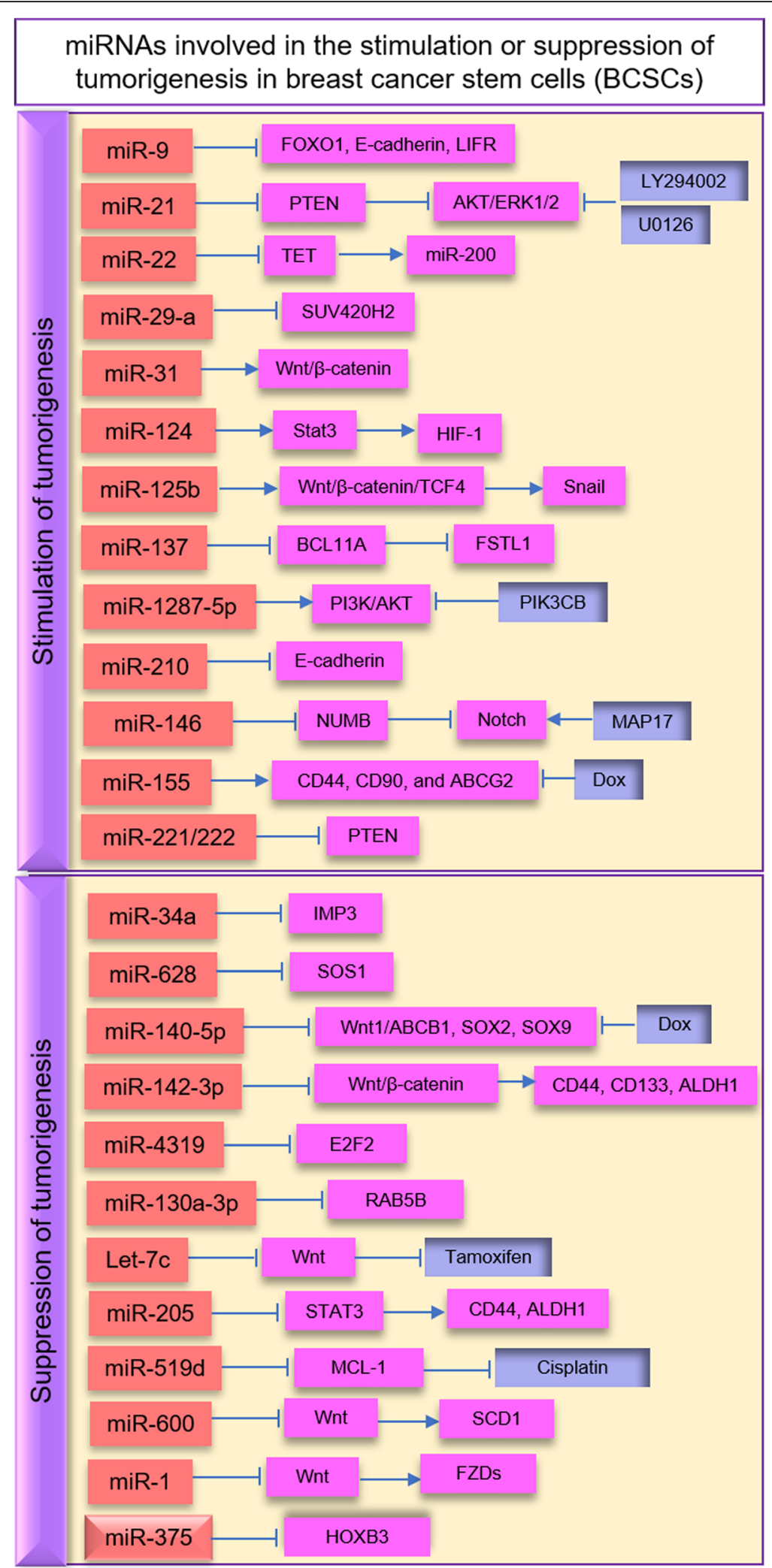

Fig. 3 miRNAs involved in the stimulation or suppression of tumorigenesis in breast cancer stem cells (BCSCs) 
the carcinogenic features of BCSCs [159, 160]. miRNA Let-7 has been shown to block the Wnt pathway, inhibit the growth and stemness of BCSCs, and promote the anti-cancer effect of tamoxifen (a chemotherapeutic drug) [161]. Recent work has also identified Let-7c through estrogen-activated Wnt signaling can suppress the self-renewal abilities of BCSCs [162]. miR-205 via modulating STAT3 signaling reduces the expression of CD44 and ALDH1 stem-cell markers and inhibits BCSC migration and invasion [163]. miR-519d by targeting MCL-1 (a member of the proapoptotic Bcl-2 family) increases the sensitivity of BCSC to cisplatin (a chemotherapeutic drug) [164]. miR-600 through the Wnt pathway targets stearoyl desaturase 1 (SCD1) and reduces BCSC self-renewal and tumorigenicity [165]. Also, miRNA-1 has been identified that targets frizzled receptors (FZDs) in the Wnt pathway and decreases BCSC proliferation and metastasis [166]. miR-375 by degrading the HOXB3 gene reduces BCSC phenotypes, EMT, and tamoxifen resistance [167]. Therefore, tumorsuppressing miRNAs with their functional pathways could be introduced as an effective strategy for targeting BCSCs $[168,169]$.

\section{Conclusion}

Several signal transduction pathways, including Wnt $/ \beta$ catenin, hedgehog, Notch, BMPs, and PI3K/Akt/NFkB, are deregulated in BCSCs. These signaling pathways stimulate proliferation, migration, invasion, EMT, chemotherapy, and radiotherapy resistance in BCSCs. miRNAs also through several signaling pathways can regulate the stemness features and tumorigenesis of BCSCs. Inhibition of key signaling pathways with small molecule inhibitors, nanoparticles, herbal medicine, and genetic modifications might be effective therapeutic approaches for targeting BCSCs [31, 85, 170, 171].

\begin{abstract}
Abbreviations
ALDH: Aldehyde dehydrogenase; BC: Breast cancer; BCICs: Breast cancerinitiating cells; BCSCs: Breast cancer stem cells; BLBC: Basal-like breast cancer; DKK: DICKKOPF protein; Dox: Doxorubicin; DNMT: DNA methyltransferase; ESA: Epithelial-specific antigen; EMT: Epithelial-to-mesenchymal transition; EGFRs: Epidermal growth factor receptors; ER: Estrogen receptor; FAK: Focal adhesion kinase; FACS: Fluorescence-activated cell sorting; GLI-1: Gliomaassociated oncogene-1; HA: Hyaluronic acid; HER2: Human epidermal growth factor receptor-2; Hh: Hedgehog; hTERT: Human telomerase; IGFII: Insulin-like growth factor II; IMP3: IGFII mRNA-binding protein; MMP3: Matrix metalloproteinase 3; NFkB: Nuclear factor kappa B; NRP2: Neuropilin-2; OCT4: Transcription factor 4; OPN: Osteopontin; PKB: Protein kinase B; PR: Progesterone receptor; ProCr: Protein C receptor; PTEN: Phosphatase and tensin homolog; RUNX2: Runt-related transcription factor 2; RTK: Receptor tyrosine kinase; SCD1: Stearoyl desaturase 1; SFRPs: Secreted frizzled-related proteins; SOS1: SOS Ras/Rac guanine nucleotide exchange factor 1; SMO: Smoothened; Tbx3: Tbox transcription factor 3; TG2: Transglutaminase; TET: Ten eleven translocations; TNBCSC: TNBC-associated BCSCs
\end{abstract}

\section{Authors' contributions}

Dr. Kai Song and Dr. Maryam Farzaneh have made contributions to the writing of the manuscript, the design of the figures, and the revision of the manuscript. All authors have approved the submitted version of the article and have agreed to be personally accountable for the author's own contributions and to ensure that questions related to the accuracy or integrity of any part of the work. All authors read and approved the final manuscript.

\section{Funding}

Not applicable.

\section{Availability of data and materials}

The datasets used and/or analyzed during the current study are available from the corresponding authors on reasonable request.

\section{Declarations}

Ethics approval and consent to participate

Not applicable.

\section{Consent for publication}

Not applicable

\section{Competing interests}

The authors declare that they have no competing interests.

Received: 2 January 2021 Accepted: 31 March 2021

Published online: 16 April 2021

\section{References}

1. Sopik V, Sun P, Narod SA. Impact of microinvasion on breast cancer mortality in women with ductal carcinoma in situ. Breast Cancer Res Treat. 2018;167:787-95.

2. Monticciolo DL, Newell MS, Moy L, Niell B, Monsees B, Sickles EA. Breast cancer screening in women at higher-than-average risk: recommendations from the ACR. J Am Coll Radiol. 2018;15:408-14.

3. Feng Y, Spezia M, Huang S, Yuan C, Zeng Z, Zhang L, et al. Breast cancer development and progression: risk factors, cancer stem cells, signaling pathways, genomics, and molecular pathogenesis. Genes Dis. 2018:5:77-106.

4. Ali SMNM. Characterization of female breast tumors using ultrasonography. In: Sudan University of science and technology; 2019.

5. Galea M. Benign breast disorders. Surgery (Oxford). 2019;37:151-6.

6. Rueda OM, Sammut S-J, Seoane JA, Chin S-F, Caswell-Jin JL, Callari M, et al. Dynamics of breast-cancer relapse reveal late-recurring ER-positive genomic subgroups. Nature. 2019;567:399-404.

7. Jia Y, Shi L, Yun F, Liu X, Chen Y, Wang M, et al. Transcriptome sequencing profiles reveal IncRNAs may involve in breast cancer (ER/PR positive type) by interaction with RAS associated genes. Pathol Res Pract. 2019;215:152405.

8. Gao X, Dong Q-Z. Advance in metabolism and target therapy in breast cancer stem cells. World J Stem Cells. 2020;12:1295.

9. Yin L, Duan J-J, Bian X-W, Yu SC. Triple-negative breast cancer molecular subtyping and treatment progress. Breast Cancer Res. 2020;22:61.

10. Simons J, Maaskant-Braat A, Luiten E, Leidenius M, van Nijnatten T, Boelens $P$, et al. Reply to: sentinel node biopsy after neoadjuvant chemotherapy for breast cancer in patients with pre-treatment node-positive: recommendation to optimize the performance. Eur J Surg Oncol. 2020;46: 218-9.

11. Thakur $\mathrm{V}$, Kutty RV. Recent advances in nanotheranostics for triple negative breast cancer treatment. J Exp Clin Cancer Res. 2019;38(1):430. https://doi. org/10.1186/s13046-019-1443-1.

12. Demissei BG, Freedman G, Feigenberg SJ, Plastaras JP, Maity A, Smith AM, et al. Early changes in cardiovascular biomarkers with contemporary thoracic radiation therapy for breast cancer, lung cancer, and lymphoma. Int J Radiat Oncol Biol Phys. 2019;103:851-60.

13. Foster B, Sindhu K, Hepel J, Wazer D, Graves T, Taneja C, et al. Threedimensional bioabsorbable tissue marker placement is associated with decreased tumor bed volume among patients receiving radiation therapy for breast cancer. Pract Radiat Oncol. 2019;9:e134-41.

14. J-w L, G-y L, Y-j J, Yan X, Pang D, Z-f J, et al. Switching to anastrozole plus goserelin vs continued tamoxifen for adjuvant therapy of premenopausal 
early-stage breast cancer: preliminary results from a randomized trial. Cancer Manag Res. 2019;11:299.

15. Nakatsukasa K, Koyama H, Ouchi Y, Sakaguchi K, Fujita Y, Matsuda T, et al. Effects of denosumab on bone mineral density in Japanese women with osteoporosis treated with aromatase inhibitors for breast cancer. J Bone Miner Metab. 2019;37:301-6.

16. Landercasper J, Ramirez LD, Borgert AJ, Ahmad HF, Parsons BM, Dietrich LL, et al. A reappraisal of the comparative effectiveness of lumpectomy versus mastectomy on breast cancer survival: a propensity score-matched update from the National Cancer Data Base (NCDB). Clin Breast Cancer. 2019;19: e481-93.

17. Tang J-Y, Ho Y, Chang C-Y, Liu H-L. Discovery of novel irreversible HER2 inhibitors for breast cancer treatment. J Biomed Sci Eng. 2019;12:225.

18. Sin WC, Lim CL. Breast cancer stem cells-from origins to targeted therapy. Stem Cell Investig. 2017:4;96.

19. Chiotaki R, Polioudaki H, Theodoropoulos PA. Stem cell technology in breast cancer: current status and potential applications. Stem Cells Cloning. 2016;9: 17.

20. Suter R, Marcum JA. The molecular genetics of breast cancer and targeted therapy. Biologics. 2007;1:241-58.

21. Luo M, Brooks M, Wicha MS. Epithelial-mesenchymal plasticity of breast cancer stem cells: implications for metastasis and therapeutic resistance. Curr Pharm Des. 2015;21(10):1301-10. https://doi.org/10.2174/1381612821 666141211120604

22. Al-Hajj M, Clarke MF. Self-renewal and solid tumor stem cells. Oncogene. 2004;23(43):7274-82. https://doi.org/10.1038/sj.onc.1207947.

23. Gangopadhyay S, Nandy A, Hor P, Mukhopadhyay A. Breast cancer stem cells: a novel therapeutic target. Clin Breast Cancer. 2013;13:7-15.

24. Olivares-Urbano MA, Griñán-Lisón C, Marchal JA, Núñez MI. CSC radioresistance: a therapeutic challenge to improve radiotherapy effectiveness in cancer. Cells. 2020;9(7):1651. https://doi.org/10.3390/cells9071651.

25. De Angelis ML, Francescangeli F, Zeuner A. Breast cancer stem cells as drivers of tumor chemoresistance, dormancy and relapse: new challenges and therapeutic opportunities. Cancers (Basel). 2019;11(10):1569. https://doi. org/10.3390/cancers11101569.

26. Wang $Y$, Zhang $Y$, Huang $Q$, Li C. Integrated bioinformatics analysis reveals key candidate genes and pathways in breast cancer. Mol Med Rep. 2018;17: 8091-100.

27. Dey P, Rathod M, De A. Targeting stem cells in the realm of drug-resistant breast cancer. Breast Cancer. 2019;11:115.

28. Palomeras S, Ruiz-Martínez S, Puig T. Targeting breast cancer stem cells to overcome treatment resistance. Molecules. 2018;23(9):2193. https://doi.org/1 0.3390/molecules 23092193.

29. Pindiprolu S K S, Krishnamurthy P T, Chintamaneni P K, Karri V V S R, Nanocarrier based approaches for targeting breast cancer stem cells. Artif Cells Nanomed Biotechnol 2018; 46: 885-898.

30. Gao Y, Tang M, Leung E, Svirskis D, Shelling A, Wu Z. Dual or multiple drug loaded nanoparticles to target breast cancer stem cells. RSC Adv. 2020;10: 19089-105.

31. Du F-Y, Zhou Q-F, Sun W-J, Chen G-L. Targeting cancer stem cells in drug discovery: current state and future perspectives. World I Stem Cells. 2019;11: 398-420.

32. Scioli MG, Storti G, D'Amico F, Gentile P, Fabbri G, Cervelli V, et al. The role of breast cancer stem cells as a prognostic marker and a target to improve the efficacy of breast cancer therapy. Cancers (Basel). 2019;11:1021.

33. Al-Hajj M, Wicha MS, Benito-Hernandez A, Morrison SJ, Clarke MF. Prospective identification of tumorigenic breast cancer cells. Proc Natl Acad Sci U S A. 2003;100:3983-8.

34. Badve S, Nakshatri H. Breast-cancer stem cells-beyond semantics. Lancet Oncol. 2012;13:e43-8.

35. Alanazi IO, Khan Z, Understanding EGFR. Signaling in breast cancer and breast cancer stem cells: overexpression and therapeutic implications. Asian Pac J Cancer Prev. 2016;17:445-53.

36. Ko CCH, Chia WK, Selvarajah GT, Cheah YK, Wong YP, Tan GC. The role of breast cancer stem cell-related biomarkers as prognostic factors. Diagnostics. 2020;10:721.

37. Tan S, Yamashita A, Gao SJ, Kurisawa M. Hyaluronic acid hydrogels with defined crosslink density for the efficient enrichment of breast cancer stem cells. Acta Biomater. 2019;94:320-9.

38. Yang F, Xu J, Tang L, Guan X. Breast cancer stem cell: the roles and therapeutic implications. Cell Mol Life Sci. 2017;74:951-66.
39. Yousefnia S, Seyed Forootan F, Seyed Forootan S, Nasr Esfahani MH, Gure AO, Ghaedi K. Mechanistic pathways of malignancy in breast cancer stem cells. Front Oncol. 2020;10:452. https://doi.org/10.3389/fonc.2020.00452.

40. Kim S J, Owen S C, Hyaluronic acid binding to CD44S is indiscriminate of molecular weight. Biochimica et Biophysica Acta (BBA)-Biomembranes. 2020; 1862(9):183348

41. Schabath H, Runz S, Joumaa S, Altevogt P. CD24 affects CXCR4 function in pre-B lymphocytes and breast carcinoma cells. J Cell Sci. 2006;119:314-25.

42. Zhou J, Chen Q, Zou Y, Chen H, Qi L, Chen Y. Stem cells and cellular origins of breast cancer: updates in the rationale, controversies, and therapeutic implications. Front Oncol. 2019;9:820.

43. Clark DW, Palle K. Aldehyde dehydrogenases in cancer stem cells: potential as therapeutic targets. Ann Transl Med. 2016;4(24):518. https://doi.org/10.21 037/atm.2016.11.82.

44. Tomita H, Tanaka K, Tanaka T, Hara A. Aldehyde dehydrogenase $1 \mathrm{~A} 1$ in stem cells and cancer. Oncotarget. 2016;7:11018-32.

45. Vassalli G. Aldehyde dehydrogenases: not just markers, but functional regulators of stem cells. Stem Cells Int. 2019;2019:3904645.

46. Liu X, Gao J, Sun Y, Zhang D, Liu T, Yan Q, et al. Mutation of N-linked glycosylation in EpCAM affected cell adhesion in breast cancer cells. Biol Chem. 2017:398:1119-26.

47. Enciu A-M, Radu E, Popescu ID, Hinescu ME, Ceafalan LC. Targeting CD36 as biomarker for metastasis prognostic: how far from translation into clinical practice? Biomed Res Int. 2018;2018:7801202.

48. Pascual G, Avgustinova A, Mejetta S, Martín M, Castellanos A, Attolini CS-O, et al. Targeting metastasis-initiating cells through the fatty acid receptor CD36. Nature. 2017;541(7635):41-5. https://doi.org/10.1038/nature20791.

49. Nilendu P, Kumar A, Kumar A, Pal JK, Sharma NK. Breast cancer stem cells as last soldiers eluding therapeutic burn: a hard nut to crack. Int I Cancer. 2018;142:7-17.

50. Collina F, Di Bonito M, Li Bergolis V, De Laurentiis M, Vitagliano C, Cerrone M, Nuzzo F, Cantile M, Botti G. Prognostic value of cancer stem cells markers in triple-negative breast cancer. Biomed Res Int. 2015;2015:158682.

51. Turashvili G, Brogi E. Tumor heterogeneity in breast cancer. Front Med. 2017;:4:227.

52. Fumagalli C, Ranghiero A, Gandini S, Corso F, Taormina S, De Camilli E, et al. Inter-tumor genomic heterogeneity of breast cancers: comprehensive genomic profile of primary early breast cancers and relapses. Breast Cancer Res. 2020;22:1-11.

53. Xiaobin Z, Chengxiao L, Jie Y, Haoqiang W, Guoqing W, Yingpeng L, Chen $N$. Breast cancer stem cells, heterogeneity, targeting therapies and therapeutic implications. Pharmacol Res. 2021;163:105320.

54. Strietz J, Stepputtis SS, Follo M, Bronsert P, Stickeler E, Maurer J. Human primary breast cancer stem cells are characterized by epithelialmesenchymal plasticity. Int J Mol Sci. 2021;22:1808.

55. Lorico A, Rappa G. Phenotypic heterogeneity of breast cancer stem cells. Oncol. 2011;2011:135039.

56. Tang DG. Understanding cancer stem cell heterogeneity and plasticity. Cell Res. 2012;22(3):457-72. https://doi.org/10.1038/cr.2012.13.

57. Geng S-Q, Alexandrou AT, Li JJ. Breast cancer stem cells: multiple capacities in tumor metastasis. Cancer Lett. 2014;349:1-7.

58. Barriga V, Kuol N, Nurgali K, Apostolopoulos V. The complex interaction between the tumor micro-environment and immune checkpoints in breast cancer. Cancers (Basel). 2019;11(8):1205. https:/doi.org/10.3390/cancers11081205.

59. Takebe N, Miele L, Harris PJ, Jeong W, Bando H, Kahn M, et al. Targeting Notch, Hedgehog, and Wnt pathways in cancer stem cells: clinical update. Nat Rev Clin Oncol. 2015;12:445-64.

60. Koury J, Zhong L, Hao J. Targeting signaling pathways in cancer stem cells for cancer treatment. Stem Cells Int. 2017:2017:2925869.

61. Yang Y, Li X, Wang T, Guo Q, Xi T, Zheng L. Emerging agents that target signaling pathways in cancer stem cells. J Hematol Oncol. 2020;13:60.

62. Xu X, Zhang M, Xu F, Jiang $\mathrm{S}$. Wnt signaling in breast cancer: biological mechanisms, challenges and opportunities. Mol Cancer. 2020;19:1-35.

63. Clarke MF. Clinical and therapeutic implications of cancer stem cells. N Engl J Med. 2019;380:2237-45.

64. Park S-Y, Choi J-H, Nam J-S. Targeting cancer stem cells in triple-negative breast cancer. Cancers. 2019;11(7):965. https://doi.org/10.3390/cancers11 070965.

65. Kim Y-J, Kim JY, Lee N, Oh E, Sung D, Cho T-M, et al. Disulfiram suppresses cancer stem-like properties and STAT3 signaling in triple-negative breast cancer cells. Biochem Biophys Res Commun. 2017:486:1069-76. 
66. Al-Othman N, Alhendi A, Ihbaisha M, Barahmeh M, Alqaraleh M, Al-Momany BZ. Role of CD44 in breast cancer. Breast Dis. 2020;39(1):1-13. https://doi. org/10.3233/BD-190409.

67. Kwong LN, Dove WF. APC and its modifiers in colon cancer. Adv Exp Med Biol. 2009;656:85-106.

68. Schmitt M, Metzger M, Gradl D, Davidson G, Orian-Rousseau V. CD44 functions in Wnt signaling by regulating LRP6 localization and activation. Cell Death Differ. 2015;22:677-89.

69. Xu H, Niu M, Yuan X, Wu K, Liu A. CD44 as a tumor biomarker and therapeutic target. Exp Hematol Oncol. 2020;9:36.

70. Vikram R, Chou WC, Hung S-C, Shen C-Y. Tumorigenic and metastatic role of CD44/-/low /CD24 $4^{\text {-low }}$ cells in luminal breast cancer. Cancers (Basel). 2020; 12:1239.

71. Jang G-B, Kim J-Y, Cho S-D, Park K-S, Jung J-Y, Lee H-Y, et al. Blockade of Wnt/ $\beta$-catenin signaling suppresses breast cancer metastasis by inhibiting CSC-like phenotype. Sci Rep. 2015:5:12465

72. Xu H, Tian Y, Yuan X, Wu H, Liu Q, Pestell RG, et al. The role of CD44 in epithelial-mesenchymal transition and cancer development. Onco Targets Ther. 2015;8:3783-92.

73. Chung SS, Aroh C, Vadgama JV. Constitutive activation of STAT3 signaling regulates hTERT and promotes stem cell-like traits in human breast cancer cells. PLoS One. 2013;8:e83971.

74. Xu X, Zhang M, Xu F, Jiang S. Wnt signaling in breast cancer: biological mechanisms, challenges and opportunities. Mol Cancer. 2020;19:165.

75. Shi J, Wang Y, Zeng L, Wu Y, Deng J, Zhang Q, et al. Disrupting the interaction of BRD4 with diacetylated Twist suppresses tumorigenesis in basal-like breast cancer. Cancer Cell. 2014;25:210-25.

76. Jiang S, Zhang M, Zhang Y, Zhou W, Zhu T, Ruan Q, et al. WNT5B governs the phenotype of basal-like breast cancer by activating WNT signaling. Cel Commun Signal. 2019;17:1-19.

77. Liu Z, Liu H, Desai S, Schmitt DC, Zhou M, Khong HT, et al. miR-125b functions as a key mediator for snail-induced stem cell propagation and chemoresistance. J Biol Chem. 2013;288:4334-45.

78. Ma SY, Park J-H, Jung H, Ha S-M, Kim Y, Park DH, et al. Snail maintains metastatic potential, cancer stem-like properties, and chemoresistance in mesenchymal mouse breast cancer TUBO-P2J cells. Oncol Rep. 2017:38: 1867-76.

79. Wang D, Cai C, Dong X, Yu QC, Zhang XO, Yang L, et al. Identification of multipotent mammary stem cells by protein $C$ receptor expression. Nature. 2015:517:81-4.

80. de Visser KE, Ciampricotti M, Michalak EM, Tan DWM, Speksnijder EN, Hau CS, et al. Developmental stage-specific contribution of LGR5+ cells to basal and luminal epithelial lineages in the postnatal mammary gland. J Pathol. 2012:228:300-9.

81. Pindiprolu SKSS, Krishnamurthy PT, Chintamaneni PK. Pharmacological targets of breast cancer stem cells: a review. Naunyn Schmiedeberg's Arch Pharmacol. 2018;391(5):463-79. https://doi.org/10.1007/s00210-018-1479-3.

82. Zhao Z, Lu P, Zhang H, Xu H, Gao N, Li M, et al. Nestin positively regulates the $\mathrm{Wnt} / \mathrm{B}$-catenin pathway and the proliferation, survival and invasiveness of breast cancer stem cells. Breast Cancer Res. 2014;16(4):408. https://doi. org/10.1186/s13058-014-0408-8

83. Klarmann GJ, Decker A, Farrar WL. Epigenetic gene silencing in the Wnt pathway in breast cancer. Epigenetics. 2008:3:59-63.

84. Pathania R, Ramachandran S, Elangovan S, Padia R, Yang P, Cinghu S, et al. DNMT1 is essential for mammary and cancer stem cell maintenance and tumorigenesis. Nat Commun. 2015;6:6910.

85. Abetov D, Mustapova Z, Saliev T, Bulanin D, Batyrbekov K, Gilman CP. Novel small molecule inhibitors of cancer stem cell signaling pathways. Stem Cell Rev Rep. 2015;11:909-18.

86. Zhang $Y$, Wang $X$. Targeting the $W n t / \beta$-catenin signaling pathway in cancer. J Hematol Oncol. 2020;13:1-16.

87. Hallett RM, Kondratyev MK, Giacomelli AO, Nixon AM, Girgis-Gabardo A, Ilieva D, et al. Small molecule antagonists of the Wnt/beta-catenin signaling pathway target breast tumor-initiating cells in a Her2/Neu mouse model of breast cancer. PLoS One. 2012;7:e33976.

88. Xu L, Zhang L, Hu C, Liang S, Fei X, Yan N, et al. WNT pathway inhibitor pyrvinium pamoate inhibits the self-renewal and metastasis of breast cancer stem cells. Int J Oncol. 2016:48:1175-86.

89. Huang P, Chen A, He W, Li Z, Zhang G, Liu Z, et al. BMP-2 induces EMT and breast cancer stemness through Rb and CD44. Cell Death Discov. 2017:3: 17039.
90. Chen A, Wang D, Liu X, He S, Yu Z, Wang J. Inhibitory effect of BMP-2 on the proliferation of breast cancer cells. Mol Med Rep. 2012;6:615-20.

91. Bach D-H, Park HJ, Lee SK. The dual role of bone morphogenetic proteins in cancer. Mol Ther Oncolytics. 2018;8:1-13.

92. Bach D-H, Park HJ, Lee SK. The dual role of bone morphogenetic proteins in cancer. Mol Ther Oncolytics. 2017:8:1-13.

93. Abdullah MF, Muhamad M, Ab-Rahim S. The role of bone morphogenetic protein 2 in the reprogramming of cancer stem cells; 2019.

94. Di Mauro C, Rosa R, D'Amato V, Ciciola P, Servetto A, Marciano R, et al. Hedgehog signalling pathway orchestrates angiogenesis in triple-negative breast cancers. Br J Cancer. 2017;116:1425-35.

95. Goel HL, Pursell B, Chang C, Shaw LM, Mao J, Simin K, et al. GLI1 regulates a novel neuropilin-2/a6ß1 integrin based autocrine pathway that contributes to breast cancer initiation. EMBO Mol Med. 2013;5(4):488-508. https://doi. org/10.1002/emmm.201202078.

96. Ge X, Lyu P, Gu Y, Li L, Li J, Wang Y, et al. Sonic hedgehog stimulates glycolysis and proliferation of breast cancer cells: modulation of PFKFB3 activation. Biochem Biophys Res Commun. 2015;464:862-8.

97. Habib JG, O'Shaughnessy JA. The hedgehog pathway in triple-negative breast cancer. Cancer Med. 2016;5:2989-3006.

98. Mercurio AM. VEGF/neuropilin signaling in cancer stem cells. Int J Mol Sci. 2019;20:490

99. Fan P, Fan S, Wang H, Mao J, Shi Y, Ibrahim MM, et al. Genistein decreases the breast cancer stem-like cell population through Hedgehog pathway. Stem Cell Res Ther. 2013:4:1-10.

100. Wang L, Duan W, Kang L, Mao J, Yu X, Fan S, et al. Smoothened activates breast cancer stem-like cell and promotes tumorigenesis and metastasis of breast cancer. Biomed Pharmacother. 2014;68:1099-104.

101. Zhang N, Kong X, Yan S, Yuan C, Yang Q. Huaier aqueous extract inhibits proliferation of breast cancer cells by inducing apoptosis. Cancer Sci. 2010; 101:2375-83.

102. Simões BM, O'Brien CS, Eyre R, Silva A, Yu L, Sarmiento-Castro A, et al. Antiestrogen resistance in human breast tumors is driven by JAG1-NOTCH4dependent cancer stem cell activity. Cell Rep. 2015:12:1968-77.

103. Zhou L, Wang D, Sheng D, Xu J, Chen W, Qin Y, et al. NOTCH4 maintains quiescent mesenchymal-like breast cancer stem cells via transcriptionally activating SLUG and GAS1 in triple-negative breast cancer. Theranostics. 2020:10:2405.

104. Bai J-W, Wei M, Li J-W, Zhang G-J. Notch signaling pathway and endocrine resistance in breast cancer. Front Pharmacol. 2020;11. https://doi.org/10.33 89/fphar.2020.00924

105. Zhang $Y, X u B$, Zhang X-P. Effects of miRNAs on functions of breast cancer stem cells and treatment of breast cancer. Onco Targets Ther. 2018;11:4263-70.

106. Shimono Y, Mukohyama J, Nakamura S, Minami H. MicroRNA regulation of human breast cancer stem cells. J Clin Med. 2015;5(1). https://doi.org/10.33 90/jcm5010002.

107. Garcia-Heredia JM, Lucena-Cacace A, Verdugo-Sivianes EM, Pérez M, Carnero A. The cargo protein MAP 17 (PDZK1IP1) regulates the cancer stem cell pool activating the Notch pathway by abducting NUMB. Clin Cancer Res. 2017;23:3871-83.

108. Bawadood AS, Al-Abbasi FA, Anwar F, El-Halawany AM, Al-Abd AM. 6Shogaol suppresses the growth of breast cancer cells by inducing apoptosis and suppressing autophagy via targeting notch signaling pathway. Biomed Pharmacother. 2020;128:110302. https://doi.org/10.1016/j.biopha.2020.1103 02.

109. Schott AF, Landis MD, Dontu G, Griffith KA, Layman RM, Krop I, et al. Preclinical and clinical studies of gamma secretase inhibitors with docetaxel on human breast tumors. Clin Cancer Res. 2013;19:1512-24.

110. Ramaswamy B, Lu Y, Teng KY, Nuovo G, Li X, Shapiro CL, et al. Hedgehog signaling is a novel therapeutic target in tamoxifen-resistant breast cancer aberrantly activated by PI3KNAKT pathway. Cancer Res. 2012;72(19):5048-59. https://doi.org/10.1158/0008-5472.CAN-12-1248.

111. Ji X, Lu Y, Tian H, Meng X, Wei M, Cho WC. Chemoresistance mechanisms of breast cancer and their countermeasures. Biomed Pharmacother. 2019; 114:108800

112. Zhao R, Kaakati RN, Hollenbeck ST, Li CY. Epidermal growth factor receptor target in breast cancer treatment. J Am Coll Surg. 2018;227:e80

113. Han $M$, Liu M, Wang $Y$, Chen $X, X u$ J, Sun $Y$, et al. Antagonism of miR-21 reverses epithelial-mesenchymal transition and cancer stem cell phenotype through AKT/ERK1/2 inactivation by targeting PTEN. Plos One. 2012;7: e39520. 
114. Korkaya H, Paulson A, lovino F, Wicha MS. HER2 regulates the mammary stem/progenitor cell population driving tumorigenesis and invasion. Oncogene. 2008;27:6120-30.

115. Nami B, Wang Z. HER2 in breast cancer stemness: a negative feedback loop towards trastuzumab resistance. Cancers. 2017;9:40.

116. Duru N, Candas D, Jiang G, Li JJ. Breast cancer adaptive resistance: HER2 and cancer stem cell repopulation in a heterogeneous tumor society. J Cancer Res Clin Oncol. 2014;140:1-14.

117. Tabolacci C, De Martino A, Mischiati C, Feriotto G, Beninati S. The role of tissue transglutaminase in cancer cell initiation, survival and progression. Med Sci. 2019;7:19.

118. Willmer T, Cooper A, Peres J, Omar R, Prince S. The T-Box transcription factor 3 in development and cancer. Biosci Trends. 2017;11:254-66.

119. Fillmore CM, Gupta PB, Rudnick JA, Caballero S, Keller PJ, Lander ES, et al. Estrogen expands breast cancer stem-like cells through paracrine FGF/Tbx3 signaling. Proc Natl Acad Sci. 2010;107:21737-42

120. Dong G, Ma G, Wu R, Liu J, Liu M, Gao A, et al. ZFHX3 promotes the proliferation and tumor growth of ER-positive breast cancer cells likely by enhancing stem-like features and MYC and TBX3 transcription. Cancers. 2020;12(11):3415. https://doi.org/10.3390/cancers12113415.

121. Fritz AJ, Hong D, Boyd J, Kost J, Finstaad KH, Fitzgerald MP, et al. RUNX transcription factor mediated control of breast cancer stem cells. J Cell Physiol. 2020;235(10):7261-72. https://doi.org/10.1002/jcp.29625.

122. Liu P, Wang Z, Brown S, Kannappan V, Tawari PE, Jiang W, et al. Liposome encapsulated Disulfiram inhibits NFKB pathway and targets breast cancer stem cells in vitro and in vivo. Oncotarget. 2014;5:7471-85.

123. Lee JJ, Loh K, Yap Y-S. PI3K/Akt/mTOR inhibitors in breast cancer. Cancer Biol Med. 2015;12:342-54

124. Ortega MA, Fraile-Martínez O, Asúnsolo Á, Buján J, García-Honduvilla N, Coca S. Signal transduction pathways in breast cancer: the important role of PI3K/Akt/mTOR. J Oncol. 2020;2020:9258396.

125. Holmes FA, Espina V, Liotta LA, Nagarwala YM, Danso M, Mclntyre K, et al. Pathologic complete response after preoperative anti-HER2 therapy correlates with alterations in PTEN, FOXO, phosphorylated Stat5, and autophagy protein signaling. BMC Res Notes. 2013;6:1-10.

126. Zhuang J, Huo Q, Yang F, Xie N. Perspectives on the role of histone modification in breast cancer progression and the advanced technological tools to study epigenetic determinants of metastasis. Front Genet. 2020;11:603552.

127. Völker-Albert M, Bronkhorst A, Holdenrieder S, Imhof A. Histone modifications in stem cell development and their clinical implications. Stem Cell Rep. 2020;15:1196-205

128. Pei J, Wang Y, Li Y, Identification of key genes controlling breast cancer stem cell characteristics via stemness indices analysis. J Transl Med. 2020;18:1-15

129. Yao $Q$, Chen $Y$, Zhou $X$. The roles of microRNAs in epigenetic regulation. Curr Opin Chem Biol. 2019;51:11-7

130. Ali Syeda Z, Langden SSS, Munkhzul C, Lee M, Song SJ. Regulatory mechanism of microRNA expression in cancer. Int J Mol Sci. 2020;21:1723.

131. Bao-Caamano A, Rodriguez-Casanova A, Diaz-Lagares A. Epigenetics of circulating tumor cells in breast cancer. Adv Exp Med Biol. 2020;1220:117-34.

132. Chi Y, Wang D, Wang J, Yu W, Yang J. Long non-coding RNA in the pathogenesis of cancers. Cells. 2019;8(9):1015. https://doi.org/10.3390/ cells8091015.

133. Yousefi H, Maheronnaghsh M, Molaei F, Mashouri L, Reza Aref A, Momeny $\mathrm{M}$, et al. Long noncoding RNAs and exosomal IncRNAs: classification, and mechanisms in breast cancer metastasis and drug resistance. Oncogene. 2020:39:953-74

134. Wu Y, Shao A, Wang L, Hu K, Yu C, Pan C, Zhang S. The Role of IncRNAs in the Distant Metastasis of Breast Cancer. Front Oncol. 2019;9:407.

135. Li L, Meng D, Wang R. Long non-coding RNA SOX21-AS1 enhances the stemness of breast cancer cells via the Hippo pathway. FEBS Open Bio. 2020;11(1):251-64.

136. Singh R, Mo Y-Y. Role of microRNAs in breast cancer. Cancer Biol Ther. 2013; $14: 201-12$.

137. Ding L, Gu H, Xiong X, Ao H, Cao J, Lin W, et al. MicroRNAs involved in carcinogenesis, prognosis, therapeutic resistance and applications in human triple-negative breast cancer. Cells. 2019;8:1492.

138. Khan AQ, Ahmed El, Elareer NR, Junejo K, Steinhoff M, Uddin S. Role of miRNA-regulated cancer stem cells in the pathogenesis of human malignancies. Cells. 2019;8:840.
139. Si W, Shen J, Zheng H, Fan W. The role and mechanisms of action of microRNAs in cancer drug resistance. Clin Epigenetics. 2019;11:25.

140. Das PK, Siddika M, Asha SY, Aktar S, Rakib M, Khanam JA, et al. MicroRNAs, a promising target for breast cancer stem cells. Mol Diagn Ther. 2019;24:6983

141. Song SJ, Poliseno L, Song MS, Ala U, Webster K, Ng C, et al. MicroRNAantagonism regulates breast cancer stemness and metastasis via TET-familydependent chromatin remodeling. Cell. 2013;154:311-24.

142. LV C, Li F, Li X, Tian Y, Zhang Y, Sheng X, et al. MiR-31 promotes mammary stem cell expansion and breast tumorigenesis by suppressing Wnt signaling antagonists. Nat Commun. 2017;8:1036.

143. Wu Y, Shi W, Tang T, Wang Y, Yin $X$, Chen $Y$, et al. miR-29a contributes to breast cancer cells epithelial-mesenchymal transition, migration, and invasion via down-regulating histone $\mathrm{H} 4 \mathrm{~K} 20$ trimethylation through directly targeting SUV420H2. Cell Death Dis. 2019:10:176.

144. Liu C, Xing H, Guo C, Yang Z, Wang Y, Wang Y. MiR-124 reversed the doxorubicin resistance of breast cancer stem cells through STAT3/HIF-1 signaling pathways. Cell Cycle. 2019;18:2215-27.

145. Schwarzenbacher D, Klec C, Pasculli B, Cerk S, Rinner B, Karbiener M, et al MiR-1287-5p inhibits triple negative breast cancer growth by interaction with phosphoinositide 3-kinase CB, thereby sensitizing cells for PI3Kinase inhibitors. Breast Cancer Res. 2019;21:20.

146. Cheng S, Huang Y, Lou C, He Y, Zhang Y, Zhang Q. FSTL1 enhances chemoresistance and maintains stemness in breast cancer cells via integrin B3/Wnt signaling under miR-137 regulation. Cancer Biol Ther. 2019;20(3): 328-37. https://doi.org/10.1080/15384047.2018.1529101.

147. Tang T, Yang Z, Zhu Q, Wu Y, Sun K, Alahdal M, Zhang Y, Xing Y, Shen Y, Xia T, Xi T, Pan Y, Jin L. Up-regulation of miR-210 induced by a hypoxic microenvironment promotes breast cancer stem cells metastasis, proliferation, and self-renewal by targeting E-cadherin. Faseb j. 2018;32(12): 6965-81.

148. Zuo J, Yu Y, Zhu M, Jing W, Yu M, Chai H, et al. Inhibition of miR-155, a therapeutic target for breast cancer, prevented in cancer stem cell formation. Cancer Biomark. 2018;21:383-92.

149. Cheng CW, Yu JC, Hsieh YH, Liao WL, Shieh JC, Yao CC, et al. Increased cellular levels of microRNA-9 and microRNA-221 correlate with cancer stemness and predict poor outcome in human breast cancer. Cell Physiol Biochem. 2018:48:2205-18.

150. Li X, Zeng Z, Wang J, Wu Y, Chen W, Zheng L, et al. MicroRNA-9 and breast cancer. Biomed Pharmacother. 2020;122:109687.

151. Li B, Lu Y, Yu L, Han X, Wang H, Mao J, et al. miR-221/222 promote cancer stem-like cell properties and tumor growth of breast cancer via targeting PTEN and sustained Akt/NF-kB/COX-2 activation. Chem Biol Interact. 2017; 277:33-42.

152. Zhou K, Liu M, Cao Y. New insight into microRNA functions in cancer: oncogene-microRNA-tumor suppressor gene network. Front Mol Biosci. 2017:4:46.

153. Bonetti P, Climent M, Panebianco F, Tordonato C, Santoro A, Marzi MJ, et al. Dual role for miR-34a in the control of early progenitor proliferation and commitment in the mammary gland and in breast cancer. Oncogene. 2019; 38:360-74.

154. Lin C, Gao B, Yan X, Lei Z, Chen K, Li Y, et al. MicroRNA 628 suppresses migration and invasion of breast cancer stem cells through targeting SOS1. Onco Targets Ther. 2018;11:5419-28.

155. Wolfson B, Eades G, Zhou Q. Roles of microRNA-140 in stem cell-associated early stage breast cancer. World J Stem Cells. 2014;6:591.

156. Wu D, Zhang J, Lu Y, Bo S, Li L, Wang L, et al. miR-140-5p inhibits the proliferation and enhances the efficacy of doxorubicin to breast cancer stem cells by targeting Wnt1. Cancer Gene Ther. 2019;26:74-82.

157. Troschel FM, Böhly N, Borrmann K, Braun T, Schwickert A, Kiesel L, et al. miR142-3p attenuates breast cancer stem cell characteristics and decreases radioresistance in vitro. Tumour Biol. 2018:40:1010428318791887.

158. Chu J, Li Y, Fan X, Ma J, Li J, Lu G, et al. MiR-4319 suppress the malignancy of triple-negative breast cancer by regulating self-renewal and tumorigenesis of stem cells. Cell Physiol Biochem. 2018;48(2):593-604. https://doi.org/10.1159/000491888.

159. Kong $X$, Zhang J, Li J, Shao J, Fang L. MiR-130a-3p inhibits migration and invasion by regulating RAB5B in human breast cancer stem cell-like cells. Biochem Biophys Res Commun. 2018;501:486-93. 
160. Pan Y, Wang R, Zhang F, Chen Y, Lv Q, Long G, et al. MicroRNA-130a inhibits cell proliferation, invasion and migration in human breast cancer by targeting the RAB5A. Int J Clin Exp Pathol. 2015;8:384-93.

161. Sun X, Xu C, Xiao G, Meng J, Wang J, Tang SC, et al. Breast cancer stem-like cells are sensitized to tamoxifen induction of self-renewal inhibition with enforced Let-7c dependent on Wnt blocking. Int J Mol Med. 2018;41(4): 1967-75. https://doi.org/10.3892/ijmm.2018.3388.

162. Sun X, Xu C, Tang SC, Wang J, Wang H, Wang P, et al. Let-7c blocks estrogen-activated Wnt signaling in induction of self-renewal of breast cancer stem cells. Cancer Gene Ther. 2016;23(4):83-9. https://doi.org/10.103 8/cgt.2016.3.

163. Mayoral-Varo V, Calcabrini A, Sánchez-Bailón M P, Martín-Pérez J, miR205 inhibits stem cell renewal in SUM159PT breast cancer cells. Plos One 2017; 12: e0188637.

164. Xie Q, Wang S, Zhao Y, Zhang Z, Qin C, Yang X. MiR-519d impedes cisplatin-resistance in breast cancer stem cells by down-regulating the expression of MCL-1. Oncotarget. 2017;8:22003-13.

165. El Helou R, Pinna G, Cabaud O, Wicinski J, Bhajun R, Guyon L, et al. miR-600 acts as a bimodal switch that regulates breast cancer stem cell fate through WNT signaling. Cell Rep. 2017;18:2256-68.

166. Liu T, Hu K, Zhao Z, Chen G, Ou X, Zhang H, et al. MicroRNA-1 downregulates proliferation and migration of breast cancer stem cells by inhibiting the Wnt/B-catenin pathway. Oncotarget. 2015;6:41638-49.

167. Fu H, Fu L, Xie C, Zuo WS, Liu YS, Zheng MZ, et al. miR-375 inhibits cancer stem cell phenotype and tamoxifen resistance by degrading HOXB3 in human ER-positive breast cancer. Oncol Rep. 2017:37:1093-9.

168. Bozorgi A, Khazaei S, Khademi A, Khazaei M. Natural and herbal compounds targeting breast cancer, a review based on cancer stem cells. Iran J Basic Med Sci. 2020;23(8):970-83. https://doi.org/10.22038/ijbms.2020.43745.10270.

169. Scioli MG, Storti G, D'Amico F, Gentile P, Fabbri G, Cervelli V, et al. The role of breast cancer stem cells as a prognostic marker and a target to improve the efficacy of breast cancer therapy. Cancers. 2019;11:1021.

170. Li W, Yang H, Li X, Han L, Xu N, Shi A. Signaling pathway inhibitors target breast cancer stem cells in triple-negative breast cancer. Oncol Rep. 2019; 41(1):437-46. https://doi.org/10.3892/or.2018.6805.

171. Zhu Q, Shen Y, Chen X, He J, Liu J, Zu X. Self-renewal signalling pathway inhibitors: perspectives on therapeutic approaches for cancer stem cells. Onco Targets Ther. 2020;13:525-40.

\section{Publisher's Note}

Springer Nature remains neutral with regard to jurisdictional claims in published maps and institutional affiliations. 